\title{
PENGARUH KONSENTRASI Carboxymethyl Cellulose (CMC) TERHADAP SIFAT FISIKOKIMIA DAN ORGANOLEPTIK SELAI KOPI DENGAN CARRIER LABU KUNING (Curcubita moschata Duchesne)
}

\author{
(The Effect of Carboxymethyl Cellulose (CMC) Concentration on \\ Physicochemical and Organoleptic Properties of Coffee Jam with Yellow \\ Pumpkin (Curcubita moschata Duchesne) as Carrier)
}

\author{
Alvina Handoyo ${ }^{a^{*}}$, Thomas Indarto Putut Suseno ${ }^{\mathrm{a}}$ \\ aFakultas Teknologi Pertanian, Univeritas Katolik Widya Mandala Surabaya \\ ${ }^{*}$ Penulis korespondensi \\ Email: alvina.handoyo@gmail.com
}

\begin{abstract}
Jam is fruit-based food product that is added water and sugar and processed to obtain the appropriate consistency. Coffee can be used to make jam. Coffee productivity in Indonesia is high but the consumption is very low. Adding carrier and thickener is needed to obtain the desired physical characteristics. This study used Pumpkin (Curcubita moschata Duchesne) as carrier and Carboxymethyl Cellulose (CMC) as thickener. CMC has wide $\mathrm{pH}$ range, ie 3-11 with optimum $\mathrm{pH}$ 5-10 so it usable in coffee jams that have $\mathrm{pH}$ 5-6. The purpose of this study was to determine effect of CMC concentration on physicochemical and organoleptic properties of coffee jam. The research design used was Randomized Block Design (RAK) with one factor, ie CMC concentration, namely 0.60\% (P1); 0.90\% (P2); 1.20\% (P3); $1.50 \%$ (P4); $1.80 \%$ (P5); $2.10 \%$ (P6) of fruit pulp weight. Best treatment was obtained by counting the area of triangle from parameters Aw, taste, flavour, mouthfeel. Repetition is done four times. Other parameters tested were spreadability, viscosity, sineresis, and color. Based on the results of the research, there is influence of CMC concentration on physicochemical and organoleptic properties of coffee jam with pumpkin as carrier. Increased CMC concentrations cause decrease Aw, spreadbaility and sineresis and increased viscosity. Average consumer preference for flavors 3,82-4,11, mouthfeel 4,284,82, aroma 4,24-5,14 with scale score 1-7. The best treatment was 0,60\% CMC with area of triangle 68,0353, Aw 0,930, spreadability 24,91 $\mathrm{cm}^{2}$, viscosity $9442,25 \mathrm{cP}$, sineresis 5,06-12,53\% and panelist preference level to taste is slightly dislike, mouthfeel is neutral, aroma is slightly like.
\end{abstract}

Keywords: cofee jam, yellow pumkin, CMC

\begin{abstract}
ABSTRAK
Selai merupakan produk pangan berbahan dasar buah yang ditambahkan air dan gula dan diproses hingga diperoleh konsistensi sesuai. Kopi adalah bahan yang dapat digunakan untuk membuat selai. Produktivitas kopi di Indonesia tinggi namun konsumsinya masih sangat rendah. Perlu ditambahkan carrier dan pengental agar diperoleh karakteristik fisik selai yang diinginkan. Pada penelitian ini digunakan Labu kuning (Curcubita moschata Duchesne) sebagai carrier dan Carboxymethyl Cellulose (CMC) sebagai pengental. CMC memiliki rentang $\mathrm{pH}$ yang cukup luas, yaitu 3-11 dengan $\mathrm{pH}$ optimum 510 sehingga dapat digunakan pada selai kopi yang memiliki $\mathrm{pH}$ 5-6. Tujuan penelitian ini adalah mengetahui pengaruh konsentrasi CMC terhadap sifat fisikokimia dan organoleptik selai kopi. Rancangan penelitian yang digunakan adalah Rancangan Acak Kelompok (RAK) dengan satu faktor, yaitu konsentrasi CMC, yaitu 0,60\% (P1); 0,90\% (P2); 1,20\% (P3); 1,50\% (P4); 1,80\% (P5); 2,10\% (P6) dari berat bubur buah. Pengulangan dilakukan sebanyak empat kali. Perlakuan terbaik diperoleh dengan menghitung luas segitiga dari parameter $A_{w}$, rasa, aroma, mouthfeel. Parameter lain yang diuji yaitu daya oles, viskositas, sineresis, dan warna. Berdasarkan hasil penelitian diketahui ada pengaruh konsentrasi CMC terhadap sifat fisikokimia dan organoleptik selai kopi dengan carrier labu kuning. Peningkatan
\end{abstract}


konsentrasi CMC menyebabkan penurunan $A_{w}$, daya oles dan sineresis serta peningkatan viskositas. Rata-rata kesukaan konsumen terhadap rasa 3,82-4,11, mouthfeel 4,28-4,82, aroma 4,24-5,14 dengan skala skor 1-7. Perlakuan terbaik dengan luas segitiga $68,0353, A_{w} 0,930$, daya oles $24,91 \mathrm{~cm}^{2}$, viskositas $9442,25 \mathrm{cP}$, sineresis 5,06-12,53\%, tingkat kesukaan panelis terhadap rasa agak tidak suka, mouthfeel netral, aroma agak suka adalah selai dengan konsentrasi CMC 0,60\%

Kata kunci: selai kopi, labu kuning, CMC

\section{PENDAHULUAN}

Selai merupakan produk pangan olahan yang berbahan dasar buah yang bisa merupakan buah utuh, bagian dari buah maupun bubur buah dengan atau tanpa penambahan konsentrat buah atau sari buah yang dicampur dengan bahan pemanis, dengan atau tanpa penambahan air yang diproses hingga diperoleh konsistensi yang sesuai (FAO, 2009). Secara umum buah yang digunakan untuk membuat selai adalah buah yang kaya akan pektin, namun buah yang memiliki kandungan pektin rendah juga bisa dibuat menjadi selai dengan penambahan pektin atau bahan pembentuk gel lainnya (Linggawati, 2017). Kopi adalah salah satu bahan selain buah yang dapat digunakan sebagai bahan untuk membuat selai.

Kopi merupakan salah satu sumber pendapatan negara Indonesia. Namun, sebagian besar produksi kopi di Indonesia adalah untuk diekspor. Volume biji kopi yang diekspor pada bulan September 2016 adalah sebesar 267.058 ton, yaitu sekitar $40 \%$ dari total produksi kopi (Kementrian Pertanian, 2016). Industri pengolahan kopi di Indonesia saat ini hanya mampu menyerap sekitar 32\% total produksi dalam negeri, dan sisanya 68\% untuk diekspor (Sudjarmoko, 2013). Pengolahan kopi menjadi selai kopi merupakan diversifikasi dalam rangka mengembangkan produk industri pengolahan kopi di Indonesia. Kopi umumnya dikonsumsi dengan diseduh atau dilarutkan dengan air. Namun dengan adanya selai kopi masyarakat tidak perlu repot menyeduh kopi.

Kopi yang digunakan dalam pembuatan selai kopi adalah ekstrak kopi yang diperoleh dengan cara menyeduh kopi instan menggunakan air panas. Agar diperoleh selai kopi dengan karakteristik fisik yang diinginkan, maka perlu ditambahkan bahan lain sebagai carrier . Carrier adalah bahan tambahan pangan yang digunakan untuk memfasilitasi penanganan, aplikasi bahan pangan dengan cara melarutkan, mengencerkan, mendispersikan, atau memodifikasi secara fisik tanpa mengubah fungsinya dan tidak mempunyai efek teknologi pada pangan (BPOM, 2013). Pada penelitian ini digunakan buah labu kuning sebagai carrier. Labu kuning (Curcubia moschata Duchesne) memiliki daging buah yang sangat tebal dan ketersediaannya di Indonesia melimpah. Pemanfaatan labu kuning masih terbatas, yaitu dikukus untuk kolak, manisan, dodol, sehingga pengolahan labu kuning untuk selai kopi merupakan diversifikasi pangan.

Labu kuning mengandung pektin sebesar 2,7 gram per 100 gram buah (Laga, 2010) Oleh karena itu, ditambahkan bahan pembentuk gel lain, yaitu Carboxymethyl Cellulose (CMC). Pemilihan CMC didasarkan pada rentang $\mathrm{pH}$ CMC yang cukup luas, yaitu 3-11 dengan $\mathrm{pH}$ optimum 5-10, sehingga dapat digunakan pada berbagai produk pangan (Mulya, 2002). Selai kopi memiliki pH antara 5-6 sehingga penggunaan CMC dapat digunakan sebagai pembentuk gel secara optimal. Pada penelitian pendahuluan, penggunaan $\mathrm{CMC}$ dengan konsentrasi $0,8 \%, 1 \%$, hingga 1,2\% masih menghasilkan daya oles selai yang baik. Daya oles, tekstur, dan viskositas selai akan menentukan penerimaan konsumen. Oleh karena itu, perlu dilakukan penelitian mengenai pengaruh konsentrasi 
Carboxymethyl Cellulose (CMC) terhadap karakteristik fisik dan organoleptik selai kopi.

\section{BAHAN DAN METODE}

\section{Bahan penelitian}

Bahan yang digunakan dalam pembuatan selai dalam penelitian ini adalah buah labu kuning (Curcubita moschata Duchesne.), CMC (CP Kelco) dengan spesifikasi seperti pada Lampiran 3, air minum dalam kemasan (aquase), gula pasir (Gulaku), dan kopi instan (Nescafe Classic).

\section{Alat untuk proses}

Alat yang digunakan untuk pembuatan selai ini adalah timbangan (Kris Chef tipe EK9150, PT. Ace Hardware Indonesia Tbk.), timbangan (Acculab ALC-3100.2, AccuLab Inc.) piring plastik, blender (Philips HR 2068, Philips Electronic Ltd.), panci teflon (Kirin), mangkuk stainless steel, kompor (Covina CX-670EXT, PT. Covina Industri Italindo), dandang (Arlisah), sendok, pisau, talenan, jar.

\section{Alat untuk analisa}

Alat yang digunakan untuk analisa selai adalah Aw meter, Bidang kaca, Brookfield Viscometer (DV-II+Pro seri 8540353, AMETEK Brookfield Inc.), kertas saring, timbangan (Acculab ALC-3100.2 AccuLab Inc.), Color Reader (Minolta CR10), dan kuesioner untuk pengujian organoleptik, botol timbang, oven, refractometer, beker gelas, pipet, botol semprot.

\section{Metode penelitian}

Pembuatan selai meliputi tahap pembuatan bubur buah labu kuning, penambahan $\mathrm{CMC}$, pemasakan, pengemasan. Formulasi pada proses pembuatan selai kopi dengan carrier labu kuning dapat dilihat pada Tabel 1. Tahap pengolahan selai kopi dengan carrier labu kuning adalah labu kuning dicuci dengan menggunakan air mengalir untuk menghilangkan kotoran yang terikut. Setelah itu dilakukan pemotongan dilakukan dengan menggunakan pisau, dengan tujuan memperkecil ukuran labu kuning sehingga mudah dikupas.

Pada tahap ini buah labu kuning dipotong menjadi 8 bagian. Kemudian labu kuning dikupas dan dihilangkan bijinya. Dari hasil pengupasan dan penghilangan biji, berat bahan yang dapat digunakan sebagai bahan untuk selai (\%BDD) adalah $77 \%$ dari berat awal labu kuning (Depkes RI, 2009). Labu kuning yang sudah bersih dikukus menggunakan dandang selama 15 menit. Tujuan pengukusan adalah untuk melunakkan tekstur labu kuning sehingga memudahkan proses selanjutnya. Labu kuning kemudian dihancurkan dengan blender kecepatan paling rendah selama 2 menit. Pada tahap penghancuran ini ditambahkan kopi yang telah dilarutkan dengan air yang telah dicampur dengan $\mathrm{Na}$ CMC dengan konsentrasi yang bervariasi, yaitu $0,60 \% ; 0,90 \% ; 1,20 \% ; 1,50 \% ; 1,80 \%$; $2,10 \%$ dari berat bubur buah. Perbandingan air dengan buah adalah 1:2 (b/b). Bubur buah kemudian dimasak dengan menggunakan api sedang dengan suhu $90^{\circ} \mathrm{C}$ dan dipertahankan selama 10 menit. Pada tahap pemasakan juga ditambahkan gula pasir sebanyak $60 \%$ dari berat bubur buah. Pengemasan dilakukan secara hot filling menggunakan jar yang telah disterilisasi sebelumnya. Sterilisasi jar dilakukan dengan mencelupkan jar ke dalam air dengan suhu $100^{\circ} \mathrm{C}$ selama 30 menit.

\section{HASIL DAN PEMBAHASAN}

Pengujian yang dilakukan pada selai kopi dengan carrier labu kuning adalah daya oles, viskositas, $A_{w}$, sineresis, dan organoleptik. Hasil pengujian dapat dilihat pada Tabel 2. 
Tabel 1. Formulasi Selai Kopi dengan Carrier Labu Kuning

\begin{tabular}{lcccccc}
\hline \multirow{2}{*}{ Bahan } & \multicolumn{7}{c}{ Perlakuan } \\
\cline { 2 - 7 } & P1 & P2 & P3 & P4 & P5 & P6 \\
\hline Buah labu kuning (g) & 200 & 200 & 200 & 200 & 200 & 200 \\
Air (g) & 100 & 100 & 100 & 100 & 100 & 100 \\
Gula pasir (g) & 180 & 180 & 180 & 180 & 180 & 180 \\
CMC (g) & 1,8 & 2,7 & 3,6 & 4,5 & 5,4 & 6,3 \\
Kopi (g) & 30 & 30 & 30 & 30 & 30 & 30 \\
Total & 511,8 & 512,7 & 513,6 & 514,5 & 515,4 & 516,3 \\
\hline
\end{tabular}

Tabel 2. Hasil Pengujian

\begin{tabular}{lcccccc}
\hline \multirow{2}{*}{ Parameter } & \multicolumn{5}{c}{ Konsentrasi CMC (\%) } \\
\cline { 2 - 6 } & 0,60 & 0,90 & 1,20 & 1,50 & 1,80 & 2,10 \\
\hline Daya Oles (cm $\left.{ }^{2}\right)$ & $24,91^{\dagger}$ & $20,23^{\mathrm{e}}$ & $18,56^{\mathrm{d}}$ & $15,55^{\mathrm{c}}$ & $12,31^{\mathrm{b}}$ & $9,70^{\mathrm{a}}$ \\
Viskositas (cP) & $9442,25^{\dagger}$ & $11595^{\mathrm{e}}$ & $12542,5^{\mathrm{d}}$ & $15657,5^{\mathrm{c}}$ & $18913,75^{\mathrm{b}}$ & $23036,25^{\mathrm{a}}$ \\
Aktivitas Air (Aw) & $0,930^{\dagger}$ & $0,921^{\mathrm{e}}$ & $0,917^{\mathrm{d}}$ & $0,910^{\mathrm{c}}$ & $0,890^{\mathrm{b}}$ & $0,860^{\mathrm{a}}$ \\
Sineresis Hari ke 7-28 (\%) & $5,06-12,53$ & $3,73-11,45$ & $3,72-9,19$ & $3,19-8,35$ & $2,36-6,24$ & $2,18-4,47$ \\
Luas & 68,0353 & 63,7324 & 60,6632 & 63,1726 & 62,5847 & 61,2144 \\
\hline
\end{tabular}

\section{Daya oles}

Daya oles merupakan salah satu uji fisik yang bertujuan untuk mengukur konsistensi dan tekstur selai pada saat dioleskan pada roti. Pengujian daya oles dilakukan secara subjektif dengan mengoleskan selai kopi dengan berat $2 \mathrm{~g}$ pada permukaan roti tawar. Hasil pengujian daya oles pada penelitian ini menunjukkan nilai daya oles yang menurun seiring meningkatnya konsentasi CMC. Hal ini disebabkan oleh semakin tinggi konsentrasi CMC, maka selai yang dihasilkan akan semakin tinggi viskositasnya sehingga selai akan semakin sulit untuk dioleskan pada roti (Pasaribu dkk., 2015).

\section{Viskositas}

Viskositas adalah resistansi suatu fluida untuk mengalir. Resistansi disebabkan oleh adanya gesekan intermolekular ketika lapisan-lapisan fluida saling bersentuhan (Špetuch et al., 2015). Hasil pengujian viskositas menunjukkan nilai yang meningkat seiring meningkatnya konsentrasi CMC. Viskositas selai semakin meningkat dengan semakin besarnya konsentrasi CMC karena CMC merupakan hidrokoloid yang dapat memerangkap air. CMC memiliki kerangka dasar 1,4- $\beta$-Dglukopiranosa sehingga dapat membentuk polimer selulosa (Kamal, 2010). Pemberian
CMC yang semakin banyak dapat meningkatkan viskositas karena adanya jembatan hidrogen antara gugus hidroksil pada air dengan gugus metil karboksil pada CMC.

\section{Aktivitas air $\left(\mathbf{A}_{\mathrm{w}}\right)$}

Pengukuran aktivitas air memberikan informasi penting tentang kualitas suatu produk, yaitu kemungkinan pertumbuhan mikroba (Sandulachi, 2016). Aktivitas air $\left(A_{w}\right)$ selai yang diperbolehkan menurut standar adalah 0,80 (USDA, 1995). Hasil pengujian aktivitas air menunjukkan nilai yang menurun dengan semakin meningkatnya konsentrasi CMC. Menurut Vibhakara and Bawa (2016), CMC dapat membentuk jaringan tiga dimensi dan dapat memerangkap air karena adanya interaksi lemah antar molekul, yaitu ikatan hidrogen dan gaya vanderwaals. Kemampuan CMC dalam memerangkap air yang menyebabkan jumlah air bebas pada selai menurun dengan semakin meningkatnya konsentrasi CMC.

\section{Sineresis}

Perbedaan konsentrasi CMC yang ditambahkan berpengaruh terhadap tingkat sineresis selai kopi. Semakin tinggi konsentrasi CMC yang ditambahkan, maka persen sineresis pada masing-masing hari 
semakin rendah karena CMC dapat memerangkap air dengan lebih kokoh dan kompak karena memiliki jumlah ikatan hidrogen yang lebih banyak. Hal ini juga didukung oleh hasil pengujian $A_{w}$. Pada pengujian $A_{w}$, semakin tinggi konsentrasi CMC maka $A_{w}$ selai makin rendah yang berarti jumlah air bebas makin sedikit. Tingkat sineresis juga mengalami peningkatan seiring dengan semakin lamanya waktu penyimpanan. Semakin lama waktu penyimpanan menyebabkan berkurangnya energi kinetik yang berperan dalam mempertahankan kestabilan matriks gel sehingga air yang terlepas makin banyak (Lefebvre and Doublier, 2005).

\section{KESIMPULAN}

Perbedaan konsentrasi CMC memberikan pengaruh nyata pada Daya Oles, Viskositas, $A_{w}$, Kesukaan terhadap Mouthfeel dan Aroma. Namun tidak memberikan beda nyata pada pengujian organoleptik terhadap Rasa. Konsentrasi CMC yang semakin meningkat menghasilkan daya oles, $A_{w}$ dan sineresis yang menurun, sedangkan nilai viskositas yang meningkat. Perlakuan terbaik yang memiliki luas terbesar adalah dengan konsentrasi CMC 0,60\%, yaitu sebesar 68,0353. Selai dengan konsentrasi CMC $0,60 \%$ memiliki daya oles $24,91 \mathrm{~cm}^{2}$, viskositas $9442,25 \mathrm{cP}, \mathrm{A}_{\mathrm{w}} \quad 0,930$ dan sineresis pada hari ke $75,06 \%$, hari ke 14 $5,98 \%$, hari ke $218,97 \%$ dan pada hari ke 28 12,53\%. Dari segi organoleptik terhadap rasa memiliki skor 3,97 , organolepik terhadap mouthfeel 4,82, organoleptik terhadap aroma 5,14.

\section{UCAPAN TERIMA KASIH}

Ucapan terima kasih saya sampaikan kepada Ir. Thomas Indarto Putut Suseno, MP., IPM dan Winda Christina Harlen, S.Gz., M.Si. selaku dosen pembimbing serta teman sekelompok selai kopi Carolina Hendrianto, Jane Nathania, Lovina Aprilia yang telah bekerja sama untuk menyelesaikan penelitian ini.

\section{DAFTAR PUSTAKA}

[FAO] Food and Agriculture Organization of the United Nation. 2009. Standard for Jams, Jellies, and Marmalades (CODEX STAN 296-2009. Juni 2018)

[USDA] United States Department of Agriculture. 1995. Water Activity in Food. https://pmp.errc.ars.usda.gov/WaterActivi ty.aspx. (19 Juni 2018)

Badan Pengawasan Obat dan Makanan. 2013. Batas Maksimum Penggunaan Bahan Tambahan Pangan Pembawa. Kepala Badan Pengawasan Obat dan Makanan. Jakarta

Departemen Kesehatan RI. 2009. Tabel Komposisi Pangan

Indonesia. Jakarta: Elex Media Computindo. http://www.fao.org/fao-whocodexalimentarius/sh-proxy/ru. November 2017)

Kamal, N. 2010. Pengaruh Bahan Aditif CMC terhadap Beberapa Parameter pada Larutan Sukrosa. J. Teknologi. 1(17):78-84.

Kementrian Pertanian. 2016. Statistik Perkebunan Indonesia 2015-2017 (Tree Corp Estate Statistic of Indonesia 20152017).http://ditjenbun.pertanian.go.id/tiny mcpuk/gambar/file/statistik/2017/Ko pi2015-2017.pdf (23 November 2017)

Lefebvre, J. and J.L. Doublier. 2005. Rheological Behavior of Polysaccharides Aqueous Systems, (dalam Polysaccharides: Structural Diversity and Functional Versatility 2nd Edition, S. Dumitriu, Ed.). New York: Marcel Dekker. 387.

Linggawati. 2017. Pengaruh Penggunaan CMC (Carboxymethyl Cellulose) Sebagai Gelling Agent terhadap Sifat Fisikokimia dan Organoleptik Selai Kawis (Limonia Acidissima). Skripsi S-1. Fakultas Teknologi Pertanian, Universitas katolik Widya Mandala Surabaya

Mulya, 2002. Mempelajari Pengaruh Penambahan Hirokoloid dan Lama Penyimpanan Terhadap Siat Fisiko 
Kimiawi dan Daya Terima Selai Renah Kalori Buah Mengkudu (Morinda citrifolia). Skripsi S-1. Jurusan Gizi Masyarakat dan Sumberaya Keluarga. Fakultas Pertanian Institut Pertanian Bogor.

Pasaribu, L.P., T. Karo-karo dan S. Ginting. 2015. Pegaruh Perbandingan Daun Lidah Buaya dengan Jagung Manis dan Konsentrasi Carboxymethyl Cellulose terhadap Mutu Selai Daun Lidah Buaya. J. Rekayasa Pangan dan Pertanian. 3(1):34-43.

Sandulachi, E. 2016. Water Activity Concept and Its Role in Food Preservation. https://www.resear
chgate.net/publication/310605656_WAT ER_ACTIVITY_CONCEPT_AND_ITS_R OLE_IN_FOOD_PRESERVATION. $(1 \overline{9}$ Špet'uch, V., J. Pētrik, E. Grambálová, D. Medved' and P. Palfy. 2015. The Capability of The Viscosity Measurement Process. Acta Metallurgica Slovaca. 21(1): 53-60.

Sudjarmoko, B. 2013. Prospek Pengembangan Industrialisasi Kopi Indonesia. Sirinov. 1(3): 99-110.

Vibhakara, H.S. and A.S. Bawa. 2006. Manufacturing Jams and Jellies in Handbook of Fruits and Fruit Processing. Blackwell Publishing: Australia 